\title{
Composite indices
}

\author{
David Roodman
}

Published online: 9 August 2011

(C) Springer Science+Business Media, LLC 2011

Composite indexes, measuring everything from state failure to access to medicines, have caught on in the last two decades. Among the lessons from the early exemplar, the HDI, are that multidimensional measures of development can be useful, at least for getting ideas across to the public; that for an index to succeed, it must have a clear, practical purpose; and that that purpose must discipline the whole index design.

Of course the HDI does not deserve sole credit for the indexing movement. Composite indexes would never have proliferated if they did not play into hardwired features of the mind. Like other primates, humans are attuned to status-to their own, to the status of others around them, to what it takes to move up. That is why organizations wishing to highlight problems, spread ideas, and prod reform are drawn to indexes. Unfortunately, in order to index they must implicitly compare incomparables such as life expectancy and money income.

Composite indexes, then, are inherently crass. In order to play to a base part of human nature, they squash the multidimensional messiness of reality onto the number line. I do not see a problem with this, as long as the aggregation methods and implied valuations are clear, and there is honesty about the goal of public communication.

I should say that grabbing attention is not the only good reason to aggregate across conceptual dimensions. Sometimes aggregation brings insight. In the Center for Global Development's annual Commitment to Development Index, which ranks wealthy countries on aid, trade, and other policies as they affect poorer nations, Japan and South Korea rank firmly at the bottom. This result was not expected and says something deep about the differences between these two Asian nations and the other 20, which are European as a matter of geography or cultural descent. In particular, the low standing of the Asian nations highlights their relative inward orientation and insularity, at least when it comes to government policy.

Still, aggregation hides at least as much as it reveals. Ravallion [3] is right to point out in his contribution that if your doctor insists on planning your care based on an

D. Roodman $(\bowtie)$

Center for Global Development, Washington, D.C., USA

e-mail: DRoodman@cgdev.org 
index of your health, you should get a new doctor. A good doctor, like a good policy maker, is an expert, someone who doesn't want her world simplified to the extreme in order to understand it. So one should aggregate measures from multiple dimensions only when the purpose is clear and realistic. It is impossible to judge the usefulness of an index without precisely stating the intended purpose.

While being artificial and crass, indexes are also mathematical abstractions, beautiful when done right, pregnant with philosophical questions. A problem comes when those devising indexes become engrossed in the mathematical and philosophical intricacies and forget the base nature of the things they are designing. If they become vague about whose attention they want to grab and why, then they are exploring an intellectual landscape without a compass of purpose. Their audience can become an abstraction too.

It is on the question of purpose that I see the most discord (and occasional confusion) among the contributions by Klugman et al. [1]; Alkire and Foster [2]; and Ravallion [3]. Klugman et al. are clear about the immediate purpose of the Human Development Index, "challenging the hegemony of growth-centric thinking," to borrow their quote from the New York Times. Thanks in part to its clear, simple structure the HDI has met that purpose, ingeniously. But the paper struggles to demonstrate more concrete impacts. The Alkire and Foster paper seems fuzzy about the concrete purpose to which its methodology can be put, leaving me skeptical, with Ravallion, of its utility. "How we measure poverty," the paper begins, "can importantly influence how we come to understand it, how we analyze it, and how we create policies to influence it." But no examples are adduced where a composite poverty index would serve experts or lay people better than simpler and/or less aggregated metrics such as headcount poverty and number of people without access to safe water.

Careful analysis of purpose also cuts the Gordian knot of Ravallion's U.S.-Zimbabwe comparison in the marginal rates of substitution between longevity and income implied in the HDI. His interpretation that a year of life is worth $\$ 9,000$ in the U.S. and $\$ 0.53$ in Zimbabwe is correct-and practically relevant for agents that can choose between a) diverting American income to prolonging American lives and b) diverting Zimbabwean income to prolonging Zimbabwean lives. But it is not the purpose of the HDI to inform such agents, because no such agents exist. The purpose, as stated, is to educate the public; and toward that end averaging the indicators arithmetically or geometrically serves well. (I favor arithmetic because it is easier for most people to understand but respect the conceptual rationale for the switch to geometric.)

Based on the evidence in these contributions, and what we know about human nature, it seems that composite indexes of poverty and development are useful mainly for educating the public. Understanding that should discipline both the devisers of indexes and their critics.

\section{References}

1. Alkire, S., Foster, J.: Understandings and misunderstandings of multidimensional poverty measurement. J. Econ. Inequal. 9(2), 289-314 (2011)

2. Klugman, J., Rodríguez, F., Choi, H.-J.: The HDI 2010: new controversies, old critiques. J. Econ. Inequal. 9(2), 249-288 (2011)

3. Ravallion, M.: On multidimensional indices of poverty. J. Econ. Inequal. 9(2), 235-248 (2011) 